$$
\begin{gathered}
\text { EPISTEME KOINONIA } \\
\text { Revista Electrónica de Ciencias de la Educación, Humanidades, Artes y Bellas Artes } \\
\text { Año II. Vol II. N4. } \\
\text { Julio - Diciembre, } 2019 \\
\text { Hecho el depósito de Ley: FA2018000022 } \\
\text { ISSN: 2665-0282 } \\
\text { FUNDACIÓN KOINONIA (F.K). } \\
\text { Santa Ana de Coro, Venezuela } \\
\text { Nolis Mercedes Martin García }
\end{gathered}
$$

http://dx.doi.org/10.35381/e.k.v2i4.522

\title{
El teatro, sus voces y experiencias para la participación comunitaria
}

\section{The theatre, their voices and experiences for community participation}

\author{
Nolis Mercedes Martin García \\ nolismarting@hotmail.com \\ Universidad Nacional Experimental Francisco de Miranda, Santa Ana de Coro \\ Venezuela \\ https://orcid.org/0000-0002-4748-9611
}

Recibido: 31 de enero de 2019

Aprobado: 1 de marzo de 2019

\section{RESUMEN}

La investigación trata sobre el papel esencial de la participación para el logro de objetivos comunes y cómo la práctica social del teatro comunitario es una estrategia que contribuye a dinamizar acciones sociales para promover la participación en el colectivo, así mismo, minimizar la desmotivación, temor o rechazo a ejercerla protagónicamente. En la comunidad el teatro comunitario encuentra su real escenario como herramienta para lograr la participación y transformación comunitaria. Activar el entramado social a través de la práctica teatral como estrategia de participación, aporta a la construcción y fortalecimiento del poder popular y la organización colectiva para, fundamentalmente tomar decisiones desde la base e incidir en lo público y en el mejoramiento de la calidad de vida.

Descriptores: teatro popular, teatro nacional, artes escénicas, cultura.

\section{ABSTRACT}

The research deals with the essential role of participation for the achievement of common objectives and how the social practice of community theater is a strategy that contributes to energizing social actions to promote participation in the collective, as well as minimizing demotivation, fear or I refuse to exercise it protagonistically. In the community, community theater finds its real stage as a tool to achieve community participation and transformation. Activating the social network through theatrical practice as a participation strategy, contributes to the construction and strengthening of popular power and collective organization to, fundamentally make decisions from the base and influence the public and improve the quality of life. 


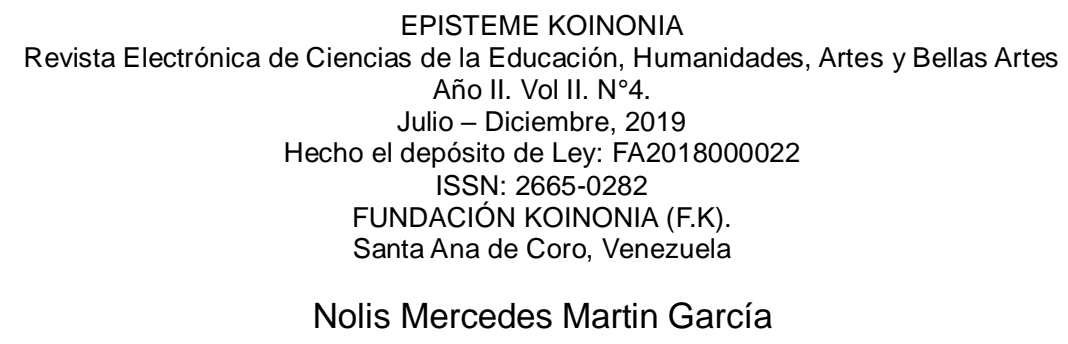

Descriptors: popular theatre, national theatre, performing arts, culture.

\section{INTRODUCCIÓN}

La experiencia que se vive en Venezuela desde 1999, se enmarca en un nuevo marco jurídico y político que ha generado significativos cambios sociales, uno de los más relevantes, la implementación de la ley de los consejos comunales y ley de las comunas. Esto demuestra que sí es posible otra forma de concebir la dinámica social, bajo los principios de solidaridad, alteridad y corresponsabilidad entre las comunidades organizadas y el Estado. La posibilidad de ejercer el derecho a tomar iniciativas y decisiones en asuntos que afectan el mejoramiento de las condiciones de vida, es uno de los logros más importantes que hoy en día suceden en algunas comunidades.

En el proceso de participación ciudadana que se desarrolla en Venezuela, las comunidades organizadas juegan un papel relevante en la consolidación de logros en pro del desarrollo de su misma comunidad, por cuanto se pretende que el crecimiento del país se inicie desde el mismo pueblo. Esta concepción, consolida en el país una serie de procedimientos legales que tipifican las orientaciones para la creación de una democracia participativa y protagónica. Las nuevas tendencias en este sentido apuntan a la creación de diferentes programas de acción que busquen iniciativas de elaboración, colaboración y redacción de diversos programas o proyectos comunitarios para crear acciones de desarrollo integrado y sostenido de la localidad.

Es esta una vía ideal para la transformación social, porque la transformación no puede pensarse sin la actuación de los seres humanos, es un hecho tremendamente humano, por tanto, la expresión cultural no puede quedar fuera de la mirada de los planes, programas y políticas gubernamentales, puesto que los poderes creadores del pueblo, como tan magníficamente lo señalo nuestro poeta Aquiles Nazoa, son un elemento propio del ser humano y al mismo tiempo una excelente arma en contra de la hegemonía y la dominación, toda revolución, todo cambio sustancial, debe empezar 


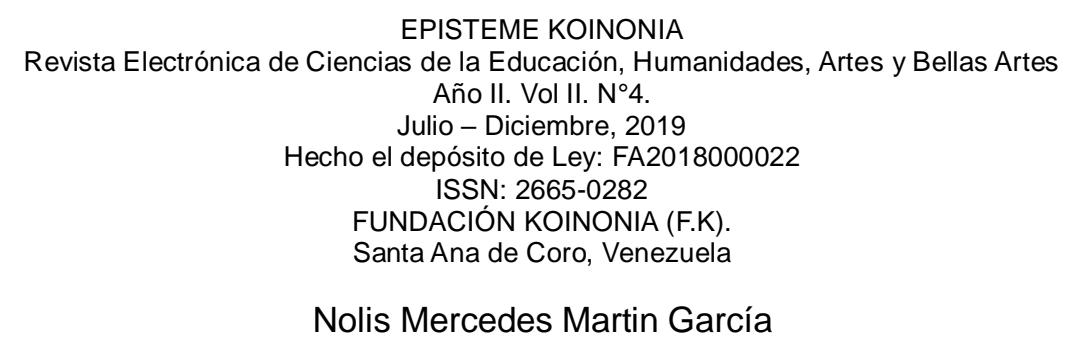

primero por lo cultural.

En esta línea de acción el teatro comunitario encuentra su real escenario como herramienta para lograr procesos de transformación sociocultural y participación. Sin embargo, a pesar de los esfuerzos que realizan habitantes de la comunidad de San José, en la ciudad de Coro por implementar mecanismos que permitan la participación activa, en muchos casos resultan infructuosos. Quizás el hecho de no haber desarrollado una cultura de participación activa, influya en que los ciudadanos y ciudadanas sientan temor o rechazo a ejercer este derecho, que en Venezuela tiene base constitucional.

\section{Propósitos de la investigación.}

La investigación plantea los siguientes propósitos:

1-. Caracterizar el teatro comunitario como estrategia de participación en la comunidad del barrio San José, municipio Miranda del estado Falcón;

2-. Diseñar experiencias de teatro comunitario para la promoción de la participación activa.

3-. Interpretar desde las voces comunitarias el significado del teatro comunitario como estrategia de participación.

\section{LA RUTA METODOLÓGICA}

Para esta investigación la ruta metodológica garantiza las condiciones tanto para aprehender como para analizar e interpretar la realidad. El estudio arroja a su vez, la necesidad de interpretar y describir la realidad con respecto al rol del teatro comunitario, en una comunidad del municipio Miranda del estado Falcón como estrategia de participación.

Lo anterior supone abordar una realidad compleja desde el punto de vista sociocultural y sociopolítico; lo que amerita enmarcar la investigación en el paradigma, socio crítico con la intencionalidad de tomar decisiones para el cambio social en atención a atender 


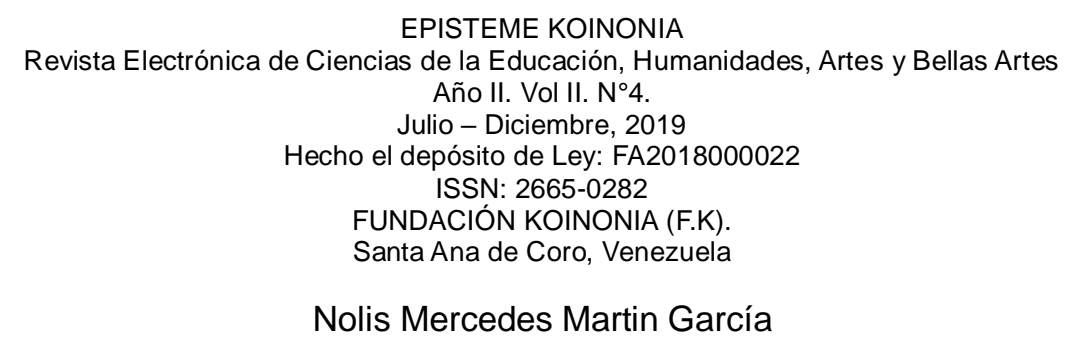

necesidades sentidas de la comunidad, para desarrollar una actitud de reflexión crítica con relación a los propios procesos de la misma. A través de este paradigma se persigue lograr conjugar dos aspectos esenciales para la investigación: los saberes populares y la acción comunitaria y por otro, el emergente interpretativo para entender el significado que le asignarán al teatro comunitario quienes a través de la experiencia lo practicará

Por tanto, para el abordaje del estudio y la generación de vivencias a partir de una experiencia de teatro comunitario, permitió entender el significado profundo que tiene esta experiencia para lograr la participación activa desde lo comunitario, encausado hacia un cambio de la conciencia pasiva hacia la conciencia participativa del colectivo, para interpretar las voces de la comunidad con respecto al teatro comunitario se utilizó el enfoque cualitativo interpretativo, basándose primordialmente en los datos. Para ello toma en cuenta el proceso de la teorización propuesto por (Martínez 2004) y sus analogías con la teoría fundamentada.

\section{Participación, teatro y comunidad.}

Según Vargas (2007), si no existe la participación de los agentes sociales, tampoco existe la cohesión en el entramado social. Por tanto es sumamente importante entender que para participar es necesario primero, organizarse. Pero, ¿qué significa participar? El término participación tiene diversas maneras de ser entendido, según (CINTEFOR 2006), citado por Vargas (2007), define la participación, como toda acción colectiva de individuos orientada a la satisfacción de determinados objetivos, esto supone la existencia de una identidad colectiva anclada en la presencia de valores, intereses y motivaciones compartidas. Una verdadera participación implica inexorablemente una inspiración liberadora para una comunidad.

Desde esta perspectiva, resulta sumamente importante la creación de situaciones donde la comunidad recree y vele por su propia cultura a través de experiencias, donde la práctica de diferentes expresiones artísticas sea una herramienta vital para 


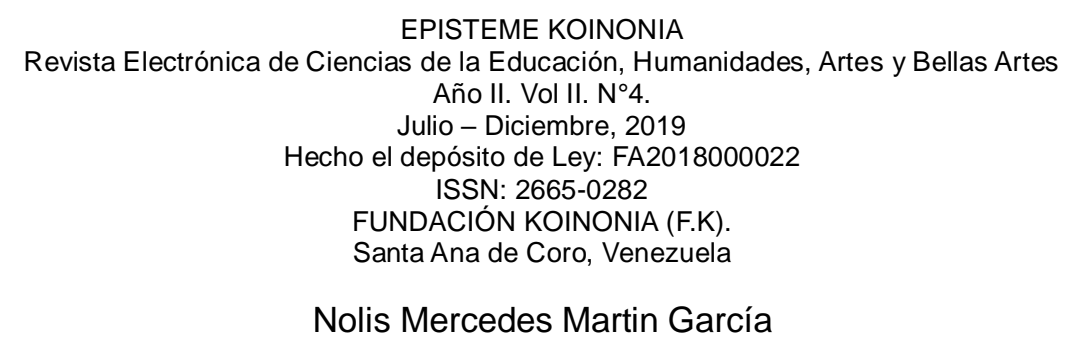

activar la energía sociocultural y desarrollar procesos de unión colectiva para lograr objetivos comunes. Este es un paso transcendental para llegar a la participación activa y protagónica.

En este mismo orden de ideas, para Sánchez (2006), la participación es un proceso educativo no formal, cuya base son las relaciones interpersonales, establecida durante la misma participación, en la cual se moldean los intereses de los actores sociales, unos y otros aprenden y enseñan conocimientos y destrezas para satisfacer expectativas colectivas.

Por otro lado Nabossa (2006), citado por Vargas (2007), expresa que la participación establece nuevos tipos y formas de relaciones sociales, al mismo tiempo que contribuye a crear que los agentes sociales mejoren sus capacidades y adquieran nuevas habilidades, e incrementen la interacción social gracias a la generación de nuevas formas de organización y gestión.

Así mismo, Harnecker y Troudi (2005), definen la participación como una dinámica mediante la cual los ciudadanos se involucran en forma consciente y voluntaria a todos los procesos que les afectan directa o indirectamente. Esto hace alusión a que el concepto no es único y no se refiere solamente al campo político. Los autores establecen que la participación se ejerce de diversas formas, por ejemplo plantean que la gente participa cuando: asiste a reuniones, cuando sale a la calle a manifestar a favor o en contra de algo, cuando vota en procesos electorales, cuando ejecuta varias tareas, cuando hace sentir su voz en una reunión. Sin embargo enfatizan que, la principal forma es la participación en la toma de decisiones que le afecten o involucren a otros y en el control de los espacios y mantenimiento en el tiempo de las medidas adoptadas.

Según lo anterior, la participación de los miembros de un grupo crea una relación de mayor compromiso, al mismo tiempo que desarrolla valores y ayuda a la integración del mismo. Importa señalar, Egg (2006), plantea que tanto los niveles como las formas de participación dependen en todo momento de los mecanismos institucionales de 


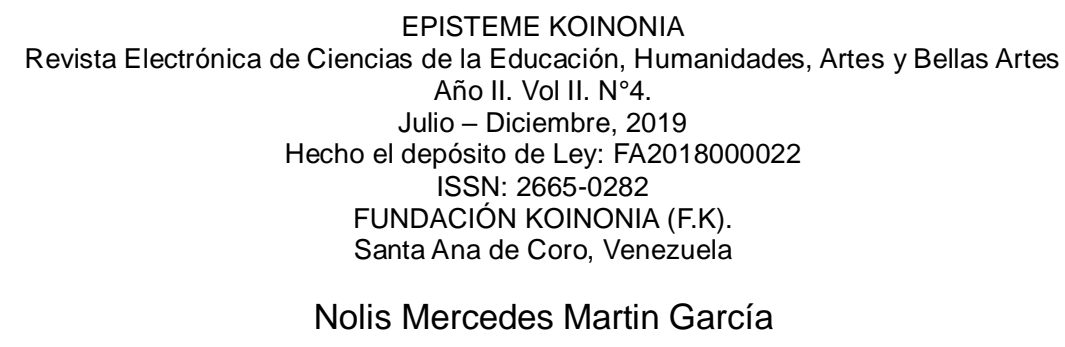

participación, pero éstos están condicionados a su vez, por el conocimiento y capacitación necesaria para ello. Por último el autor advierte con respecto al tema, que no se aprende teóricamente a participar; no es algo que se estudie: "se aprende a participar participando".

Lo anterior apunta a que la utilización del teatro es tremendamente acertada para potenciar procesos de comunicación en las comunidades, precisamente porque tiene la capacidad de mostrar realidades comunitarias como ningún otro arte, por la simple razón de que es un hecho en vivo que logra recrear personajes, circunstancias, problemas, situaciones que aquejan a la comunidad y la misma se siente reflejada en ellas, esto permite la conexión directa y, por ende, la participación.

Así lo expresa Bidegain (2007) cuando reflexiona sobre el poder transformador de lo social que aporta el teatro comunitario y como conjuga de manera firme y atenta la memoria del pasado, el interés por el presente y la utopía en el futuro. Así mismo enfatiza en el hecho de que el teatro comunitario tiene el poder de despertar conciencias e incluso levantar pueblos.

En atención a lo anterior, una de las teorías que más significado tienen para esta investigación son las expuestas por Augusto Boal (1974), el autor establece que el teatro, de manera particular, es determinado por la sociedad de manera contundente más que las demás artes, dado su contacto directo con la gente, por ende tiene mayor poder de convencimiento. La teoría del teatro del oprimido considera como base que el teatro como lenguaje, es apto para ser utilizado por cualquier persona, tenga o no aptitudes artísticas y que como práctica, el teatro puede ser puesto al servicio de la gente, para que éstos se expresen y para que, al utilizar este nuevo lenguaje, descubran a su vez nuevos contenidos, así como capacidades y destrezas antes desconocidas.

El teatro parte de la gente, de la participación de la gente, donde se involucra en convertir y hacer del teatro una práctica para la vida. Es un aprendizaje en acción, parte de la expresión misma del ser, de lo que quiere expresar, no solamente con la palabra 


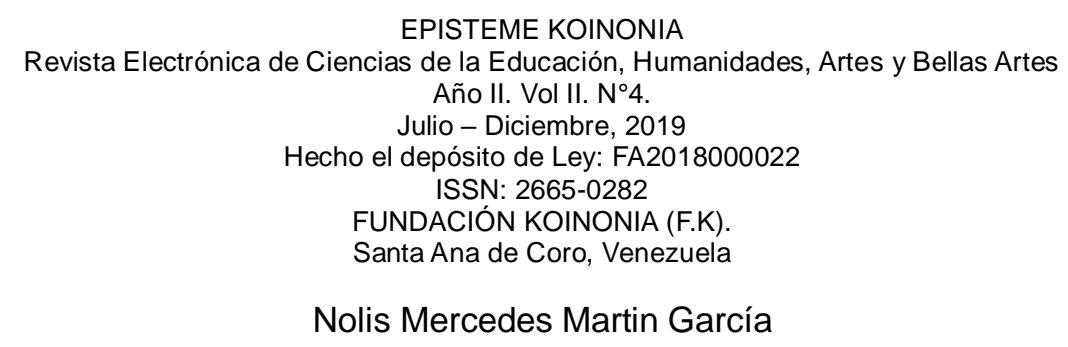

sino con todos los sentidos. De esta manera lo hace ser más combativo y porque no, que entre en conflicto con la propia realidad. Se parte de que el teatro es un hecho social, quiere decir que el teatro en su acción representa y visibiliza los hechos políticos, económicos, éticos, históricos, culturales, ecológicos e ideológicos, desde este punto de vista el teatro comunitario alcanza esa gran cúspide cuando ese ser, que es un ser político, social, espiritual, también es un ser creador, está en capacidad de crear para transformar, para transformar la conciencia, los modelos de vida, la organización de la comunidad, donde confluyen seres humanos de diferentes modos de pensar, con diferentes creencias, con diferentes modos de vida, pero que en la necesidad de expresar y buscar soluciones a los problemas comunitarios, se unen en aras de mejorar y dar respuestas a necesidades sentidas.

El teatro comunitario permite esta cohesión, y, ¿dónde pueden integrarse todas estas voces?; en la escena, la calle es la escena, los espacios comunitarios son espacios escénicos, que lo convierten en escena, aquellos que con sus experiencias y voces, lo hacen teatro en acción. No se trata simplemente de "dar una función de teatro" en una comunidad; esto sería, e teatro para la comunidad; lo cual, por supuesto, es también muy importante. Pero el objetivo fundamental del Teatro Comunitario es hacer hablar y participar a la comunidad.

El teatro se convierte así en un medio de comunicación a través del cual, la comunidad transmite sus vivencias y experiencias más significativas, de esta manera preserva y promueve la riqueza de su patrimonio cultural e histórico, fomentando un cambio cultural. Por otra parte, al comprender el valor de la utilización del teatro como una estrategia para promover el cambio social, las comunidades comienzan a tomar conciencia que, mediante la inclusión e integración de cada uno de sus miembros, pueden fortalecer la identidad colectiva y enfrentar y transformar la realidad de su entorno. 


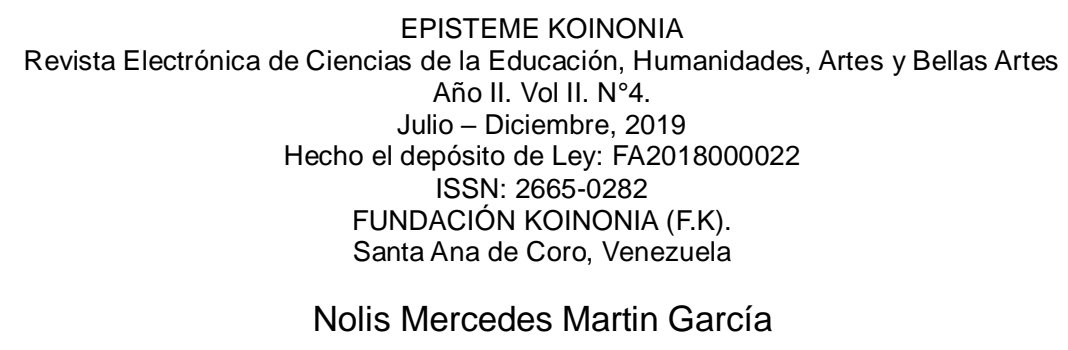

\section{Las voces de la comunidad y su relación con los supuestos teóricos}

Para la realización de esta fase se tomó como base el modelo propuesto por (Martínez 2007), sobre el proceso de la teorización, se hace alusión primordialmente al paso de la contrastación, para ello se tomó en cuenta la red de relaciones que se realizaron en el paso de la estructuración.

\section{Red de relaciones}

A partir del establecimiento de las categorías centrales, para la categoría de participación se determinaron tres dimensiones para estudiar la misma: la cultural, política y social, las relaciones con respecto a estas tres dimensiones surgieron de lo expresado por la gente acerca de cómo sienten, creen y saben de la participación y su relación con estas dimensiones. Así mismo se visualizaron los nexos que nacieron sobre lo que la gente piensa y conoce acerca del teatro, qué es, para qué sirve y si pudiera ser una estrategia para que la gente participe de otra manera.

De la red de relaciones con respecto a la categoría central: teatro comunitario, se desprendieron otras categorías nuevas que logran ampliar el análisis, entre éstas están: Cultura comunal, desarrollo humano, desarrollo endógeno, desarrollo estratégico.

\section{CONTRASTACIÓN O CODIFICACIÓN SELECTIVA}

Codificación selectiva: Es el proceso de elegir una categoría como central, y relacionar todas las demás categorías con esa, la idea central es la de encontrar una línea narrativa que permita escribir un relato que integre las diversas categorías en un conjunto de suposiciones e hipótesis.

Tal como puede observarse existen algunas similitudes con respecto al proceso de la teorización al que hace alusión (Martínez 2007) y el procedimiento de la teoría fundamentada, en este caso de la contrastación, en la teoría fundamentada sería la codificación selectiva, sin embargo (Martínez 2007), aporta una explicación más profunda con respecto a cómo realizar la relación y contrastación con teorías similares 
EPISTEME KOINONIA

Revista Electrónica de Ciencias de la Educación, Humanidades, Artes y Bellas Artes

Año II. Vol II. N4.

Julio - Diciembre, 2019

Hecho el depósito de Ley: FA2018000022

ISSN: 2665-0282

FUNDACIÓN KOINONIA (F.K).

Santa Ana de Coro, Venezuela

Nolis Mercedes Martin García

hasta detectar el vacío para que surja la suposición.

En este sentido se presenta cuadro de contrastación o codificación selectiva. Permite visualizar la manera como se contrasto la teoría referencial con los aportes de los informantes claves y su contexto, y los vacíos detectados que permiten explicar el bosquejo teórico o el acercamiento hacia lo estudiado.

Soporte teórico

Harnecker y Troudi (2005) la No asume el poder de

principal forma de decisión.

participación está en la toma de decisiones.

La participación requiere que los agentes sociales y miembros de la comunidad desarrollen tres vertientes fundamentales: tomar parte, formar parte, tener parte.

(Vargas 2007), la verdadera participación debe ser autónoma y regida por las propias organizaciones colectivas

(Antillano 2004), la comunidad necesita que sus miembros se eduquen en la participación.

(Sánchez 2006), la participación política se expresa en una intención definida de intervención en lo público.

(Egg 2006), derecho a decir su palabra y decidir su propio destino. Se aprende a participar participando.

(Bidegain 2007), poder transformador de lo social que aporta el teatro. Experiencia creativa que coadyuva a solucionar problemas.

(Boal 1974), El teatro del oprimido. El teatro al servicio de los pueblos sojuzgados.

\section{Constructo que surge}

No están fortalecidos los mecanismos

participación.

No participa, ni se organiza

Desconoce como participar en forma activa

No estimula la creatividad y la participación a partir del arte y la cultura

No incide en lo público

Desconocimiento de estrategias de participación a través de expresiones artísticas como el teatro.

No motiva la integración colectiva para el mejoramiento de la calidad de vida.

No asume a través de la experiencia teatral criticar la realidad.

No identifica su contexto cultural, dificultad para relacionarse y fortalecer la identidad colectiva (valores, intereses, motivación compartida)

No trabaja en equipo, afecta la cohesión grupal y la integración
Bosquejo teórico

Una comunidad que no participa activamente pierde el espíritu que le da sentido al hecho de ser comunidad. Activar el entramado social a través de la practica teatral como estrategia de participación, aporta a la construcción del socialismo Bolivariano en el sentido de fortalecer el poder popular y la organización colectiva para fundamentalmente tomar decisiones desde la bases e incidir en lo público y en el mejoramiento de la calidad de vida. Esto supone coadyuvar en el desarrollo endógeno, humano y estratégico de la patria. Así mismo permite la práctica de lo social a través del arte, convirtiendo estas expresiones en el desarrollo de la cultura comunal atendiendo a sus características propias.

Fuente: Autora 


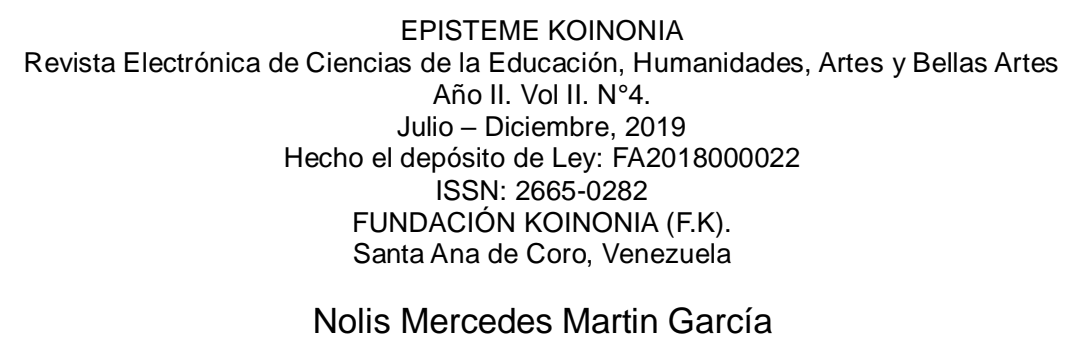

El cuadro permite observar de qué forma se contraponen la teoría referencial anteriormente analizada, con las voces de la comunidad, lo que la gente dice y define como participación, es la manera como ella la entiende y práctica en su propio contexto, atendiendo a sus características y procesos sociales. Así mismo en el cuadro denotan los vacíos encontrados a través de la contrastación, lo que permite interpretar esas voces y establecer un bosquejo teórico sobre el teatro comunitario como estrategia de participación.

\section{CONCLUSIONES Y REFLEXIONES}

A continuación las conclusiones que derivan de este proceso de teorización, sustentadas con la presentación de la interpretación que expresaron a través de sus voces los informantes claves sobre los aspectos orientadores de la investigación.

1-. El teatro comunitario debe ser visto como un instrumento transformador de realidades, en donde los actores de escena son también actores sociales, sin pretensión de protagonismo y con absoluta humildad.

2-. Para la formación de un grupo de teatro comunitario, se parte de que todos tengan la convicción de que este tipo de teatro es un arma que ayuda a solucionar problemas y planteados en una obra, todos son capaces de reconocer el problema y aportar soluciones.

3-. El teatro comunitario es un instrumento de combate pues, no solo expone los conflictos que afectan a la comunidad, sino que la participación de la gente contribuye a solucionarlos ya que toma conciencia de los mismos.

4-. El teatro comunitario es aquel que nace y se genera desde la misma gente, por tanto un grupo de personas puede formarlo de manera voluntaria, organizarse y comunicarse a través de la actividad teatral.

5-. Una comunidad que no participa activamente pierde el espíritu que le da sentido al hecho de ser comunidad. Activar el entramado social a través de la practica teatral como estrategia de participación, aporta a la construcción del socialismo Bolivariano en 


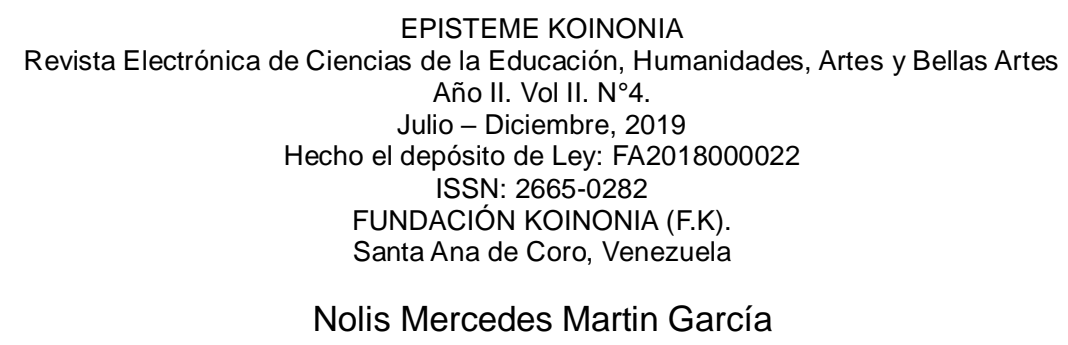

el sentido de fortalecer el poder popular y la organización colectiva para fundamentalmente tomar decisiones desde la bases e incidir en lo público y en el mejoramiento de la calidad de vida.

6-.Esto supone coadyuvar en el desarrollo endógeno, humano y estratégico de la patria. Así mismo permite la práctica de lo social a través del arte, convirtiendo estas expresiones en el desarrollo de la cultura comunal atendiendo a sus características propias.

El recorrido epistemológico, resultó ser una travesía muy interesante desde el punto de vista, no solo de formación para la investigación, sino de reconocer la importancia de los procesos investigativos y más aún, la imprescindible actitud del investigador hacia sus supuestos metodológicos, así como teóricos y su relación tanto con los informantes claves, como con su propio contexto.

En este sentido trabajar a partir del proceso de la teorización y aplicar sus pasos al área de estudio, ha sido de gran significado, el descubrimiento de nuevos aspectos ligados al estudio, logró visualizar nuevas categorías de estudio, nuevas relaciones a partir de la sistematización de experiencias.

Importa señalar que al respecto, el proceso de teorización parte en primer lugar, de un proceso mental muy lógico y que requiere de la aplicación de una serie de habilidades del pensamiento para relacionar y contraponer elementos. Sin dudas este proceso permite realizar un ejercicio intelectual para priorizar informaciones relevantes, la agudeza necesaria sale a relucir para lograr luego de clasificar la información y colocarla en una gran de red de relaciones con otras categorías, relacionarlas con las posturas de otros autores que han realizado investigaciones similares. A través del compartir de saberes con la comunidad, se logró visualizar y crear los constructos teóricos en atención a la información recabada, ya en su concepción se comienza a teorizar, pues se comienza a pensar de manera diferente, haciendo analogías, utilizando la metáfora, consiguiendo nuevos nexos, repensando, redescubriendo. 


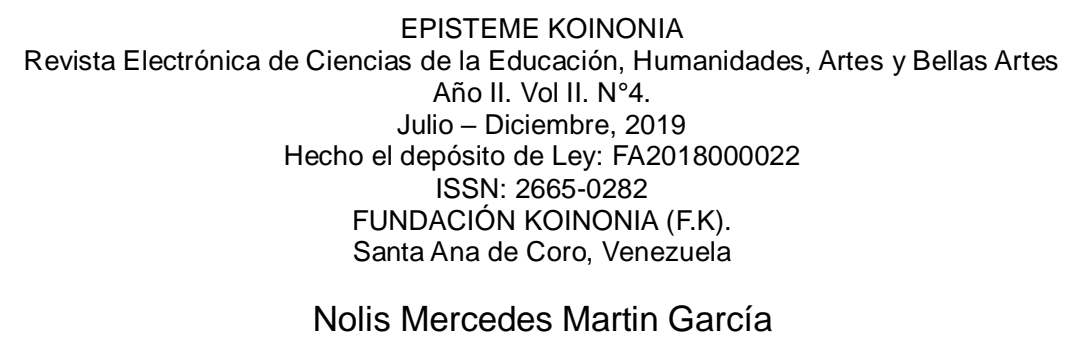

\section{REFERENCIAS}

1. Ander, E. (2007). Acción Municipal, Desarrollo local y Trabajo Comunitario. Universidad Bolivariana de Venezuela.

2. Ander, E. (2006). Metodología y Práctica de la Animación Sociocultural. Ministerio de la Cultura. Consejo Nacional de la Cultura Caracas.

3. Berthold, M. (1974). Historia Social del Teatro I. Ediciones Guadarrama. Madrid.

4. Boal, A (1974). Teatro del oprimido y otras poéticas políticas. Ediciones de la Flor. Buenos Aires. Argentina.

5. Calvo, A. (2002). La Animación Sociocultural: Una estrategia educativa para la participación. Alianza Editorial. Madrid.

6. Constitución de la República Bolivariana de Venezuela (1999) Gaceta Oficial de la República de Venezuela №36.860 (Extraordinario), Diciembre 30, 1.999.

7. Harnecker, M; Troudi, El. (2005). Herramientas para la Participación. Recuperado a partir de http://www.rebelion.org/docs/15385.pdf

8. Martínez, M. (2004). Ciencias y arte en la metodología cualitativa. México. Trillas.

9. Martínez, M. (2007). La investigación cualitativa en educación. México. Trillas.

10. Mas Herrera, M. (2005). Desarrollo Endógeno. Panapo. Venezuela.

11. Montaño, E. (2005). Liderazgo, Participación Comunitaria y Ciudadana. Popayán.

12. Murcia, J. (1990). Investigar para Cambiar. Un enfoque sobre investigación participante cooperativa. Editorial del Magisterio. Bogotá, Colombia.

13. Paz, E. (2003). Investigación cualitativa en investigación: Fundamentos y tradiciones. Mc Graw Hill (España).

(C2019 por la autora. Este artículo es de acceso abierto y distribuido según los términos y condiciones de la licencia Creative Commons Atribución-NoComercial-Compartirlgual 4.0 Internacional (CC BY-NC-SA 4.0) (https://creativecommons.org/licenses/by-nc-sa/4.0/). 